\title{
Manufacturing optimization using Tsukamoto fuzzy inference system method: A case study in block paving and solid concrete block industry
}

\author{
Sayuti, $M^{1^{*}}$, Juliananda and Diana Khairani Sofyan ${ }^{1}$ \\ ${ }^{1}$ Department of Industrial Engineering, Faculty of Engineering Universitas Malikussaleh, 24351 Aceh \\ Indonesia
}

\begin{abstract}
Fuzzy method has advantages in solving real-world problems that are mostly non-binary and non-linear, such as calculating the optimization of production quantities. A case study for the application of this method was applied in UD. Setia Kawan Company that run the production of solid concrete and block paving. The problems faced by this company is the high demand for products resulting in short stock and sometimes over stock due to unstable customer ordering and inaccurate management in production planning. From the calculations, the number of solid concrete block produced by the company on the period of October 2016, December 2016 and February 2017 was not optimal. According to Tsukamoto's FIS, the optimal number of solid concrete block in the third period is 9973,9562 and 12.087 unit of solid concrete block. While the number of block paving produced by the company on the period of November 2016, December 2016 and January 2017 was also not optimal. According to Tsukamoto's FIS analysis, the optimal number of block paving in the third period should be $9.116,10.113$ and 7.120 unit of block paving
\end{abstract}

\section{Introduction}

Production planning is very important in the decision-making of a company strategy, particularly in manufacturing companies. The determination of the optimal number of products to be produced becomes the key to proper production planning. Production planning is conducted with the aim to meet consumer demand and to improve company productivity.. UD. Kawan Setia is one of the manufacturing companies engaged in the manufacture of solid concrete block and block paving. The problem faced by this company is the high demand for the product resulting in the company often experiencing short stock and some times over stock so that it is vulnerable to product damage. This is explained by the high demand data but the low inventory data and the amount of production in the period of October 2016 to March 2017 in demand, inventory and production data for both products. The problem occurs because of unstable ordering and lack of decision-making by

\footnotetext{
* Corresponding author: sayuti_m@unimal.ac.id
} 
the management in the production planning process. Fuzzy Inference System (FIS) is an approach which can be applied to aid the decision making and to resolve the issues [1-3].

In FIS, there are three methods, which are Tsukamoto, Mamdani and Sugeno. In Tsukamoto method, each consequence of IF-Then rules has to be represented with a fuzzy set with monotonous membership functions [2]. Accordingly, the output of the interference of each rule is explicitly given (crisp) based on $\alpha$-predicate (fire strength). The end result is obtained by using a weighted average. In Mamdani method, input and output variables are divided into one or more fuzzy set(s). Consequently, the output of the interference of each rule uses the Max (maximum) method and the Additive (sum) method. The end result is numbers in the domain of the fuzzy set, where the data is processed by using some defuzzification methods on the composition rules to get the output. Conversely, in Sugeno method, which is similar to Mamdani method, the output (consequence) system is not a fuzzy set, but a constants or a linear equation [4].

The fuzzy inference system is a popular computing framework based on the concepts of fuzzy set theory, fuzzy if-then rules, and fuzzy reasoning. It has found to be a successful application in a wide variety of field, such as automatic control, data classification, decision analysis, expert systems, time series prediction, robotic, and pattern recognition [3][5]. This is because the Tsukamoto Fuzzy Inference System method can do reasoning on the same principle as human. The reasoning used by Tsukamoto's FIS is monotonous reasoning so that its output value can be calculated directly from the membership value associated with its antecedent [6]. In addition, this method has advantages that are very suitable for use in most real-world problems that are mostly non-binary and non-linear. Fuzzy Inference System Tsukamoto method is also one of a method for decision making. Especially in many uncertainties and vagueness situations, this method is very flexible and has a tolerance for any data existing [7]. The Fuzzy Inference System uses reasoning monotony in the process of solving problems. The workings of this method are to use the data production, inventory and demand data as input and then processed through the three stages of process to optimize the amount of the input of the third. The first phase, i.e. the transformation of Fuzzification input data be fuzzy sets. The second stage is the fuzzy inference process by entering the sets that has been formed into the rule. Finally, Defuzziification is the process of aggregation of fuzzy sets, fuzzy sets and changed into a crisp sets [8].

From the problem, the purpose of this research is to calculate the optimization of production number of solid concrete block and block paving by using Tsukamoto fuzzy inference system method.

\section{Methodology}

To obtain the optimal amount of production in order to remain stable so that it can increase the company profit, the following three stages of Tsukamoto's FIS were used:

I. Fuzzification. Fuzzification is the process of converting non-fuzzy variables (numerical variables) into fuzzy variables (linguistic variables) [4]. The variables that will be used must be defined first such as demand, inventory and production variable. Each variable has a fuzzy set. As an example, for inventory variable, the used fuzzy set is down, moderate, and up. Then, seek the membership value of each fuzzy set, on each variable. Membership value is obtained by representing each fuzzy set with a membership function. There are six functions that can be used which are, representation of Linear, triangular curve, the curve shape of the shoulder, s-curve, trapezoidal curve, and the curve of the oval shape 
II. Inference. Inference is the process of combining many rules based on available data. Fuzzy inference system receives crisp input. This input is then sent to a knowledge base that contains $n$ fuzzy rules in the form of IF-THEN. After determining the rules that will be used, then find the value of the antecedent membership or fire strength $(\alpha)$, and the estimated value of goods to be manufactured (z) of each rule, using the membership value of each fuzzy set. A Fuzzy inference system with a crisp output is shown in Fig.1.

III. Defuzzyfication. Determine the crisp output value will be the number of goods produced $(Z)$, by changing the input (in the form of fuzzy sets derived from the composition of fuzzy rules) into a number of fuzzy sets in the domain. Defuzzyfication method used in the Tsukamoto method is centered average method. This formulation is to determine the crisp output value that will be the number of goods produced $(Z)$, by changing the input (in the form of fuzzy sets derived from the composition of fuzzy rules) into a number of fuzzy sets in the domain. This is the centered average method equation:

$$
Z=\frac{\sum_{i=1}^{n} a i x i}{\sum_{i=1}^{n} a i}
$$

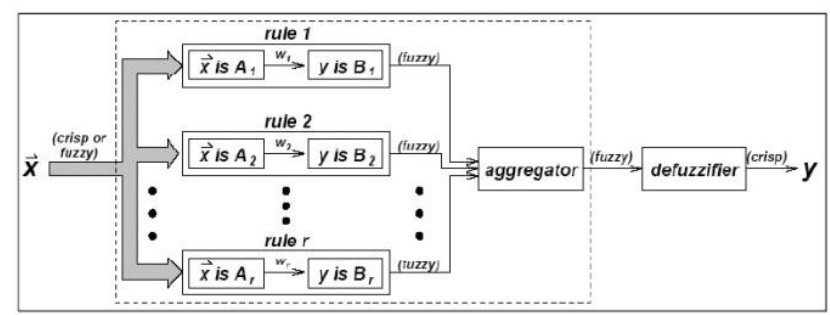

Fig. 1. Block diagram for a Fuzzy Inference System

\section{Result And Discussion}

The data of demand, stock and production amount of solid concrete block in the period Oct. 2016 - March 2017 can be seen in the Table 1, while the data of demand, stock and production amount of block paving in the same period can be seen in the Table 2 .

\subsection{Tsukamoto's FIS}

The Tsukamoto's FIS basically consists of four steps i.e. Fuzzyfication, Rule 'IF-THEN', Inference, and Defuzzyfication. Each step has its own process to get an output. The process steps of Tsukamoto's FIS method as shown in Table 3.

Table 1. Data Demand, Stock And Amount of Production Solid Concrete Block

\begin{tabular}{|c|c|c|c|}
\hline Period & $\begin{array}{c}\text { Demand } \\
\text { (units) }\end{array}$ & $\begin{array}{c}\text { Amount of Production } \\
\text { (units) }\end{array}$ & Stock (units) \\
\hline Oct-16 & 7.373 & 12.500 & 450 \\
\hline Nov-16 & 5.805 & 7.538 & 5.577 \\
\hline Des-16 & 13.975 & 7.110 & 7.310 \\
\hline Jan-17 & 15.675 & 12.652 & 445 \\
\hline Feb-17 & 10.500 & 9.700 & -2.578 \\
\hline Mar-17 & 11.900 & 12.124 & -800 \\
\hline
\end{tabular}


Table 2. Data Demand, Stock And Amount of Production Block Paving

\begin{tabular}{|c|c|c|c|}
\hline Period & Demand (units) & Amount of Production (units) & Stock (units) \\
\hline Oct-16 & 10.050 & 9.840 & 640 \\
\hline Nov-16 & 8.400 & 7.120 & 430 \\
\hline Des-16 & 10.850 & 9.800 & -850 \\
\hline Jan-17 & 6.785 & 8.780 & -1.050 \\
\hline Feb-17 & 9.745 & 10.540 & 1.995 \\
\hline Mar-17 & 11.950 & 9.650 & 2.790 \\
\hline
\end{tabular}

Table 3. The Translation of The Steps of Fis Tsukamoto Method

\begin{tabular}{|l|l|}
\hline \multicolumn{1}{|c|}{ Step } & \multicolumn{1}{c|}{ FIS Tsukamoto } \\
\hline Fuzzyfication & Non fuzzy to fuzzy or from numerical variable to linguistic variable \\
\hline Rule 'IF-THEN" & $\begin{array}{l}\text { Formation of shaped rules 'IF-THEN' is done by connecting } \\
\text { between input variables and output variables using operators "and" }\end{array}$ \\
\hline Inference & $\begin{array}{l}\text { 1. Function implication with function "min" } \\
\text { 2. The composition between rules uses monotonic reasoning }\end{array}$ \\
\hline Defuzzyfication & Calculation using the centre average defuzzifier method \\
\hline
\end{tabular}

\subsection{Fuzzyfication}

Fuzzyfication aims to turn crisp input data into fuzzy. This study used several variables in determining the amount of production. A formation of fuzzy sets is used to define crisp input values. Demand and supply as input variable and production as output variables. Universe of Discourse in this study is obtained from the lowest data and the highest data from the company. For solid concrete block product, the universe of discourse value of demand variable is $[5.805,15.675]$, inventory variable is $[-2.578,7.310]$ and production variable is $[7.110,12.625]$. As for block paving products, the universe of discourse value of demand variable is $[6,785,11,950]$, inventory variable is $[-1.050,2,790]$ and production variable is $[7,120,10,540]$. Each fuzzy set has domains whose values are in universe of discourse. The domains in fuzzy set obtained the lowest data, the lower quartile (Q1), the median (Q2) and the upper quartile (Q3) as well as the company highest data. Before calculating quartile and median values, it is needed to sort the data first. The fuzzy set value of each variable for solid concrete block and block paving products is presented in Table 4 and Table 5. There are three fuzzy variables that will be represented in membership function i.e. demand variable with small, medium, large fuzzy set, inventory variable with small, medium, large fuzzy set and production variables with reduced, permanent and increased fuzzy set.

Table 4. The Fuzzy Set Value Of Each Variable For Solid Concrete Block Manufacturing

\begin{tabular}{|c|c|c|r|r|}
\hline Function & Variable & Fuzzy Set & Universe of Discource & \multicolumn{1}{|c|}{ Domain } \\
\hline Input & \multirow{2}{*}{ Demand } & Small & {$[5.805,15.675]$} & {$[5.805,11.200]$} \\
\cline { 5 - 5 } & & Medium & & {$[7.373,13.975]$} \\
\cline { 5 - 5 } & & Large & & {$[11.200,15.675]$} \\
\cline { 3 - 4 } & \multirow{2}{*}{ Stock } & Small & {$[-2.578,7.310]$} & {$[-2.578,447,5]$} \\
\cline { 5 - 5 } & & Medium & & {$[-800,5.577]$} \\
\cline { 3 - 3 } & & Large & & {$[447,5,7.310]$} \\
\hline Output & Production & Reduced & {$[7.110,12.625]$} & {$[7.110,10.912]$} \\
\hline & & Permanent & & {$[7.538,12.500]$} \\
\hline & & Increases & & {$[10.912,12.625]$} \\
\hline
\end{tabular}


Table 5. The Fuzzy Set Value Of Each Variable For Paving Block

\begin{tabular}{|c|c|c|c|c|}
\hline Function & Variable & Fuzzy Set & Universe of Discourse & Domain \\
\hline \multirow[t]{6}{*}{ Input } & \multirow[t]{3}{*}{ Demand } & Small & \multirow[t]{3}{*}[6.785,11.950]{} & {$[6.785,9.897,5]$} \\
\hline & & Medium & & {$[8.400,10.850]$} \\
\hline & & Large & & {$[9.897,5,11.950]$} \\
\hline & \multirow[t]{3}{*}{ Stock } & Small & \multirow[t]{3}{*}[-1.050,2.790]{} & {$[-1.050,535]$} \\
\hline & & Medium & & {$[-850,1.995]$} \\
\hline & & Large & & {$[535,2.790]$} \\
\hline \multirow[t]{3}{*}{ Output } & \multirow[t]{3}{*}{ Production } & Reduced & \multirow[t]{3}{*}[7.120,10,540]{} & {$[7.120,9.725]$} \\
\hline & & Permanent & & {$[8.780,9.840]$} \\
\hline & & Increases & & {$[9.725,10.540]$} \\
\hline
\end{tabular}

\subsection{Representation of Solid Concrete Block Product Demand Variable}

The membership function of small fuzzy set used membership function of left curve shape of the shoulder. In solid concrete block product, the membership function is divided into three intervals, $[0,5.805],[5.805,11.200]$ and $[11.200, \infty]$. For the membership function of medium fuzzy set, a triangular membership function was used in which this function was divided into three intervals, [0, 7.373], [7.373, 11.200], and [11.200, 13.975]. For the membership function of large fuzzy set, increased linear membership function was used in which this function was divided into three intervals, [0, 11.200], [11.200, 15.675], and $[15.675, \infty]$. The fuzzy set of demand variable of solid concrete block products can be seen in Fig.2.

\subsection{Representation of Solid Concrete Block Products Inventory Variable}

In solid concrete block product, the membership function was divided into three intervals, $[0,-2.578],[-2.578,447.5]$ and $[447,5, \infty]$, medium fuzzy set, triangular membership function was used in which this function was divided into three intervals, [0, -800], [-800, 447.5], and [447.5, 5.577], large fuzzy set, increased linear membership function was used, in which this function was divided into three intervals, [0, 447.5], [447.5, 7.310], and $[7.310, \infty]$. Fuzzy set of inventory variable of solid concrete block products is in Fig.3.

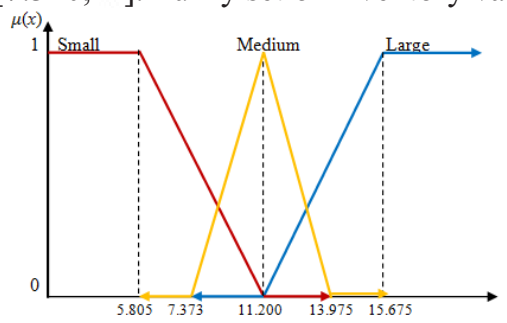

Fig.2. The fuzzy set of solid concrete block demand variable

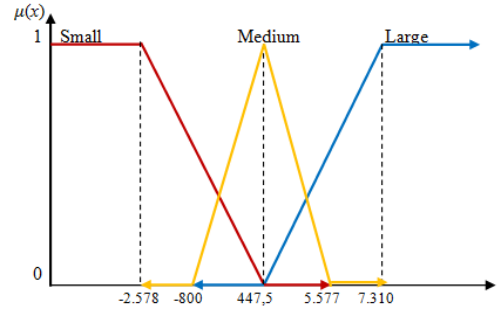

Fig.3. The fuzzy set of solid concrete block stock variable

\subsection{Representation of Solid Concrete Block Products Production Variable}

In Table 4, the membership function of decreased fuzzy set used membership function of left curve shape of the shoulder. In solid concrete block product, the membership function was divided into three intervals, [0,7.110], [7.110, 10.912] and [10.912, $\infty$, permanent fuzzy, triangular membership function was used in which this function was divided into three intervals, $[0,7.538],[7.538,10.912]$, and [10.912, 12.500], increased fuzzy, increased linear membership function was used in which this function was divided into three 
intervals, $[0,10.912],[10.912,12.625]$, and $[12.625, \infty]$. The fuzzy set of production variable for solid concrete block products can be seen in Fig.4.

\subsection{Representation of Block Paving Product Demand Variable}

From Table 5, the membership function of small fuzzy set used membership function of left curve shape of the shoulder. In solid concrete block product, the membership function was divided into three intervals, [0, 6.785], [6.785, 9897.5] and [9.897,5, $\infty$, medium fuzzy, triangular membership function was used in which this function was divided into three intervals, [0, 8.400], [8.400, 9.897,5], and [9.897,5, 10.850], large fuzzy, increased linear membership functions was used in which this function was divided into three intervals, $[0,9.897,5],[9.897,5,11.950]$, and $[11.950, \infty]$. The fuzzy set of demand variable for block paving is in Fig.5.

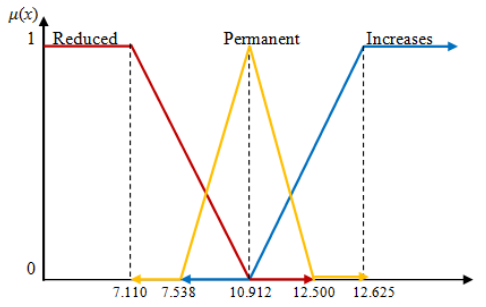

Fig. 4. The fuzzy set of solid concrete block production variable

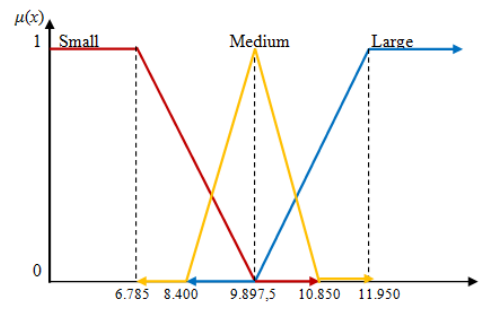

Fig.5. The fuzzy set of paving block demand variable

\subsection{Representation of Block Paving Products Inventory Variable}

In solid concrete block product, the membership function was divided into three intervals, $[0,-1.050],[-1.050,535]$ and $[535, \infty]$, for the membership function of medium fuzzy set, triangular membership function was used in which this function was divided into three intervals, [0, -850], [-850, 535], and [535, 1.995], large fuzzy, decreased linear membership was used in which this function was divided into three intervals, [0, 535], [535, 2.790], and $\left[2,790,{ }^{\infty}\right]$. The fuzzy set of paving block stock variable in Fig.6.

\subsection{Representation of Block Paving Products Production Variable}

In Table 5, decreased fuzzy set used left curve shape of the shoulder membership function. In solid concrete block product, the membership function was divided into three intervals, $[0,7.120],[7.120,9.725]$ and $[9.725, \infty]$, crisp fuzzy set, triangular membership function was used in which this function was divided into three intervals, [0, 8.780], [8.780, 9.725], and $[9.725,9.840]$, increased fuzzy set, increased linear membership function was used in which this function was divided into three intervals, [0, 9.725], [9.725, 10.540], and $\left[10.540,{ }^{\infty}\right]$. Fuzzy set of production variables for block paving is in Fig.7.

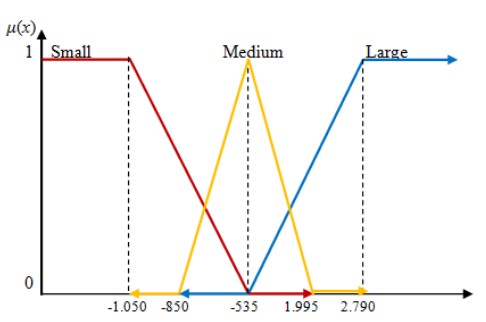

Fig.6. The fuzzy set of paving block stock variable

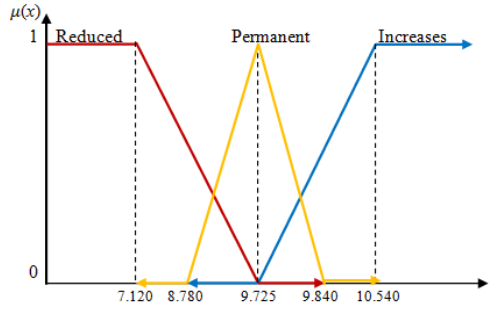

Fig.7. The fuzzy set of paving block production variable 


\subsection{Formation of Rule'IF-THEN'}

After fuzzyfication process, then the next step is to form fuzzy rule by connecting input variable and output variable. Each rule has two antecedents and one consequent. The operator used in rules formation is operator and. Each product has 27 rules. This is due to each product has three fuzzy sets for each fuzzy variable. The forming of fuzzy rule for solid concrete block and block paving product is in Tables 6 and Table 7.

Table 6. Fuzzy Rule Of Solid Concrete Block Product

\begin{tabular}{|c|c|c|c|c|c|c|}
\hline $\begin{array}{c}\text { Rul } \\
\text { e }\end{array}$ & Antecedents & Demand & Operation & Stock & Consequent & Production \\
\hline R1 & $I F$ & Large & and & Small & $T H E N$ & Increases \\
\hline R2 & $I F$ & Large & and & Small & $T H E N$ & Permanent \\
\hline R3 & $I F$ & Large & and & Small & $T H E N$ & Reduced \\
\hline R4 & $I F$ & Large & and & Medium & $T H E N$ & Increases \\
\hline R5 & $I F$ & Large & and & Medium & $T H E N$ & Permanent \\
\hline R6 & $I F$ & Large & and & Medium & $T H E N$ & Reduced \\
\hline R7 & $I F$ & Large & and & Large & $T H E N$ & Increases \\
\hline R8 & $I F$ & Large & and & Large & $T H E N$ & Permanent \\
\hline R9 & $I F$ & Large & and & Large & $T H E N$ & Reduced \\
\hline R10 & $I F$ & Medium & and & Small & $T H E N$ & Increases \\
\hline R11 & $I F$ & Medium & and & Small & $T H E N$ & Permanent \\
\hline R12 & $I F$ & Medium & and & Small & $T H E N$ & Reduced \\
\hline R13 & $I F$ & Medium & and & Medium & $T H E N$ & Increases \\
\hline R14 & $I F$ & Medium & and & Medium & $T H E N$ & Permanent \\
\hline R15 & $I F$ & Medium & and & Medium & $T H E N$ & Reduced \\
\hline R16 & $I F$ & Medium & and & Large & $T H E N$ & Increases \\
\hline R17 & $I F$ & Medium & and & Large & $T H E N$ & Permanent \\
\hline R18 & $I F$ & Medium & and & Large & $T H E N$ & Reduced \\
\hline R19 & $I F$ & Small & and & Small & $T H E N$ & Increases \\
\hline R20 & $I F$ & Small & and & Small & $T H E N$ & Permanent \\
\hline R21 & $I F$ & Small & and & Small & $T H E N$ & Reduced \\
\hline R22 & $I F$ & Small & and & Medium & $T H E N$ & Increases \\
\hline R23 & $I F$ & Small & and & Medium & $T H E N$ & Permanent \\
\hline R24 & $I F$ & Small & and & Medium & $T H E N$ & Reduced \\
\hline R25 & $I F$ & Small & and & Large & $T H E N ~$ & Increases \\
\hline R26 & $I F$ & Small & and & Large & $T H E N ~$ & Permanent \\
\hline R27 & $I F$ & Small & and & Large & $T H E N ~$ & Reduced \\
\hline
\end{tabular}

After calculating the number of solid concrete block production in the period of October 2016 - March 2017, the output can be seen in Table 8. Similarly to solid concrete block product, optimal is the best, the highest, the most profitable, the best or the highest. The output result of production quantity of block paving by using Tsukamoto's FIS can be seen in Table 9. After obtaining the optimal production result with Tsukamoto's FIS, the next step is to predict the production for the future period. The prediction method used is constant method and linear method. From the calculation of SEE (Standard Error Estimate) for both methods of predicting, then the best method is used to determine the amount of production based on demand data for the next six months period which is the linear method 
with the smallest SEE value.

Table 7. Fuzzy Rule Of Paving Block Product

\begin{tabular}{|c|c|c|c|c|c|c|}
\hline Rule & Antecedents & Demand & Operation & Stock & Consequent & Production \\
\hline R1 & $I F$ & Large & and & Small & $T H E N$ & Increases \\
\hline R2 & $I F$ & Large & and & Small & $T H E N$ & Permanent \\
\hline R3 & $I F$ & Large & and & Small & $T H E N$ & Reduced \\
\hline R4 & $I F$ & Large & and & Medium & $T H E N$ & Increases \\
\hline R5 & $I F$ & Large & and & Medium & $T H E N$ & Permanent \\
\hline R6 & $I F$ & Large & and & Medium & $T H E N$ & Reduced \\
\hline R7 & $I F$ & Large & and & Large & $T H E N$ & Increases \\
\hline R8 & $I F$ & Large & and & Large & $T H E N$ & Permanent \\
\hline R9 & $I F$ & Large & and & Large & $T H E N$ & Reduced \\
\hline R10 & $I F$ & Medium & and & Small & $T H E N$ & Increases \\
\hline R11 & $I F$ & Medium & and & Small & $T H E N$ & Permanent \\
\hline R12 & $I F$ & Medium & and & Small & $T H E N$ & Reduced \\
\hline R13 & $I F$ & Medium & and & Medium & $T H E N$ & Increases \\
\hline R14 & $I F$ & Medium & and & Medium & $T H E N$ & Permanent \\
\hline R15 & $I F$ & Medium & and & Medium & $T H E N$ & Reduced \\
\hline R16 & $I F$ & Medium & and & Large & $T H E N$ & Increases \\
\hline R17 & $I F$ & Medium & and & Large & $T H E N$ & Permanent \\
\hline R18 & $I F$ & Medium & and & Large & $T H E N$ & Reduced \\
\hline R19 & $I F$ & Small & and & Small & $T H E N$ & Increases \\
\hline R20 & $I F$ & Small & and & Small & $T H E N$ & Permanent \\
\hline R21 & $I F$ & Small & and & Small & $T H E N$ & Reduced \\
\hline R22 & $I F$ & Small & and & Medium & $T H E N$ & Increases \\
\hline R23 & $I F$ & Small & and & Medium & $T H E N$ & Permanent \\
\hline R24 & $I F$ & Small & and & Medium & $T H E N$ & Reduced \\
\hline R25 & $I F$ & Small & and & Large & $T H E N ~$ & Increases \\
\hline R26 & $I F$ & Small & and & Large & $T H E N$ & Permanent \\
\hline R27 & $I F$ & Small & and & Large & $T H E N ~$ & Reduced \\
\hline
\end{tabular}

Table 8. Output Of Production Quantities Of Solid Concrete Block With Fis Tsukamoto Method

\begin{tabular}{|c|r|r|r|r|}
\hline Period & $\begin{array}{c}\text { Demand } \\
\text { (units) }\end{array}$ & $\begin{array}{c}\text { Stock } \\
\text { (units) }\end{array}$ & $\begin{array}{c}\text { Company production } \\
\text { (units) }\end{array}$ & \multicolumn{1}{c|}{$\begin{array}{c}\text { FIS Tsukamoto } \\
\text { Production (units) }\end{array}$} \\
\hline Okt-16 & 7.373 & 450 & 12.500 & 9.937 \\
\hline Nov-16 & 5.805 & 5.577 & 7.538 & 8.061 \\
\hline Des-16 & 13.975 & 7.310 & 7.110 & 9.562 \\
\hline Jan-17 & 15.675 & 445 & 12.652 & 11.072 \\
\hline Feb-17 & 10.500 & -2.578 & 9.700 & 12.087 \\
\hline Mar-17 & 11.900 & -800 & 12.124 & 11.708 \\
\hline
\end{tabular}

Table 9. Output Of Production Quantities Of Paving Block With Fis Tsukamoto Method

\begin{tabular}{|c|r|r|r|r|}
\hline Period & $\begin{array}{c}\text { Demand } \\
\text { (units) }\end{array}$ & $\begin{array}{c}\text { Stock } \\
\text { (units) }\end{array}$ & $\begin{array}{c}\text { Company } \\
\text { production (units) }\end{array}$ & $\begin{array}{c}\text { FIS Tsukamoto } \\
\text { Production (units) }\end{array}$ \\
\hline Oct-16 & 10.050 & 640 & 9.840 & 9.571 \\
\hline Nov-16 & 8.400 & 430 & 7.120 & 9.116 \\
\hline Des-16 & 10.850 & -850 & 9.800 & 10.113 \\
\hline Jan-17 & 6.785 & -1.050 & 8.780 & 7.120 \\
\hline
\end{tabular}




\begin{tabular}{|r|r|r|r|r|}
\hline Feb-17 & 9.745 & 1.995 & 10.540 & 10.540 \\
\hline Mar-17 & 11.950 & 2.790 & 9.650 & 9.725 \\
\hline
\end{tabular}

\section{Conclusion}

The number of solid concrete blocks produced by the company in the period of October 2016, December 2016 and February 2017 according to Tsukamoto's FIS method was not optimal, while in the period of November 2016 and March 2017 was optimal according to Tsukamoto's FIS. For the period of January 2017 the company was only able to produce 12.652 solid concrete blocks. Based on Tsukamoto's FIS method, the optimal number of solid concrete block production in the three non-optimal periods is $9.973,9.562$ and 12.087 solid concrete blocks. After calculation to predict production amount of six months ahead, the best method that can be used is linier method with smallest SEE value.

The number of block paving produced by the company in the period of October 2016 based on Tsukamoto's FIS method was optimal, while the number of company production that was not been optimal was in November 2016, December 2016 and January 2017. For the period of March 2017, according to Tsukamoto's FIS, the company was only able to produce 9.725 blocks. According to Tsukamoto's FIS method, the optimal amount of production for the three non-optimal periods is 9.116, 10.113, 7.120 block paving. After calculation to predict production amount of six months ahead, the best method that can be used is linear method with smallest SEE value.

The authors of this research paper express their deep gratitude to the staff and laboratory technicians of the Department of Industrial Engineering, Universitas Malikussaleh and Management of UD. Setia Kawan Company for their help during the conducting of the research.

\section{References}

[1] K. Kumar, S. Deep, S. Suthar, M. G. Dastidar, and T. R. Sreekrishnan, Desalin. Water Treat., vol. 57, no. 21, pp. 9690-9697, (2016).

[2] A. Saepullah and S. W. Romi, J. Intell. Syst., vol. 1, no. 2, pp. 143-147, (2015)

[3] S. Yagiz and C. Gokceoglu, Expert Syst. Appl., vol. 37, no. 3, pp. 2265-2272, 2010.

[4] F. Ariani and R. Y. Endra, in 2nd International Conference on Engineering and Technology Development (ICETD 2013), pp. 189-200, (2013)

[5] A. Amindoust, S. Ahmed, A. Saghafinia, and A. Bahreininejad, Appl. Soft Comput., vol. 12 , no. 6, pp. 1668-1677, (2012)

[6] A. T. Bon and S. F. Utami, Int. J. Bus. Econ. Dev., vol. 3, no. 1, pp. 1-11, (2015)

[7] A. T. Bon and S. F. Utami, pp. 209-219, (2016)

[8] A. T. Bon and S. F. Utami, vol. 3, no. 2, pp. 102-104, (2015) 